\title{
Mis-regulating segmentation gene expression in Drosophila
}

\author{
SUSAN M. PARKHURST* and DAVID ISH-HOROWICZ \\ Developmental Genetics Laboratory, Imperial Cancer Research Fund Developmental Biology Unit, Zoology Department, University of \\ Oxford, South Parks Road, Oxford OX1 3PS, UK \\ * Present address: Division of Biology 156-29, California Institute of Technology, Pasadena, California 91125, USA
}

\begin{abstract}
Summary
We have used the hunchback (hb) gap-gene promoter to drive ectopic expression of the pair-rule genes fushi tarazu (ftz), even-skipped (eve) and hairy $(h)$. Unexpectedly, flies transformed with such constructs are viable, despite spatial and temporal mis-regulation of pair-rule expression caused by the fusion genes. We show that fusion gene expression is transcriptionally regulated, such that ectopic expression is suppressed when pattern is established, and present evidence indicating that
\end{abstract}

interstripe $h b-f t z$ expression is repressed by eve. These results are considered in terms of redundant control of pair-rule gene striping. We also discuss the potential dangers of using mis-regulated gene expression to analyse normal function.

Key words: segmentation gene expression, embryonic pattern formation, pair-rule genes, genetic redundancy, hunchback, mis-regulation, Drosophila.

\section{Introduction}

Embryonic pattern in Drosophila is initiated and refined through the expression of a hierarchy of segmentation genes (Nüsslein-Volhard and Wieschaus, 1980; reviewed in Akam, 1987; Ingham, 1988). Initially, maternal genes establish coarse positional signals that define domains of gap-gene transcription (Driever and Nüsslein-Volhard, 1988a; Driever et al. 1989; NüssleinVolhard et al. 1987; Struhl et al. 1989). Overlapping gradients of the gap-gene proteins regulate the transcription of the pair-rule genes that are expressed in a series of stripes (Gaul and Jäckle, 1989; Pankratz et al. 1989; Stanojevic et al. 1989). Pair-rule genes are expressed in different but overlapping sets of stripes (Fig. 1A) that expose individual blastoderm cells/ nuclei to different combinations of pair-rule proteins. Thus, the relative positionings of pair-rule stripes (pairrule 'phasings') define the even more precise domains of segment-polarity gene expression, such as the onecell-wide stripes of engrailed (en) and wingless $(\mathrm{wg})$ that mark parasegmental embryonic metameric boundaries (DiNardo et al. 1985; Ingham et al. 1988; Lawrence et al. 1987).

We are particularly interested in the regulation and function of the pair-rule genes, whose correct expression underlies the establishment of metameric pattern. Initial pair-rule transcription is first detected in broad domains during nuclear cleavage stage 12 , and evolves into stripes following the final blastoderm cleavage (stage 14). This occurs over a period of $15-30 \mathrm{~min}$, consistent with the extreme instability of pair-rule transcripts and proteins $\left(\mathrm{t}_{0.5} \sim 6 \mathrm{~min}\right.$; Edgar $e t$ al. 1986; Weir and Kornberg, 1985). Pair-rule gene striping is predominantly transcriptionally controlled such that transcript levels are enhanced within stripe domains and diminished between them (i.e. are repressed in the 'inter-stripes').

The pair-rule genes have been classified according to their principle striping mechanism (Howard and Ingham, 1986; Ingham and Gergen, 1988). The 'primary' pair-rule genes ( $h$, eve and runt) are thought to respond directly to gap-gene positional cues via extensive upstream promoters with independent regulatory elements ('stripe elements') for individual stripes (Howard et al. 1988; Pankratz et al. 1989; Stanojevic et al. 1989). Deletion of upstream $h$ sequences leads to the loss of specific stripes, and upstream regions can drive striped expression of $\beta$-galactosidase (lac $Z$ ) reporter genes in individual $h$ stripe domains (Howard et al. 1988; Pankratz et al. 1990; G. Riddihough and M. Lardelli, personal communication). Similarly, individual eve stripes are independently regulated (Goto et al. 1989; Harding et al. 1989). Less is known about the negative control of $h$ and eve transcription, although individual stripe elements must include repressor sites to prevent interstripe expression.

In contrast, patterning of 'secondary' pair-rule genes (e.g. $f t z$ ) is largely a response to the striping of the primary pair-rule genes. ftz striping depends on a small upstream transcriptional control element (the 'zebra' element) that confers striped expression on a lac $Z$ reporter gene, suggesting that all $f t z$ stripes respond to a similar signal (Hiromi et al. 1985; Hiromi and Gehring, 
1987; but see Dearolf et al. $1989 a$; Ueda et al. 1990). $h$ and eve are both implicated in repressing ftz expression; indeed $f t z$ stripe domains correspond to the cells that express neither $h$ nor eve (Fig. 1A; Frasch and Levine, 1987; Carroll et al. 1988; Hooper et al. 1989; IshHorowicz et al. 1989). The sites through which $h$ and $e v e$ act have not yet been defined although putative negative control elements have been defined within the ftz zebra element (Dearolf et al. 1989b).

$f t z$ and eve are further subject to positive autoregulatory control, each promoter including a domain that activates positive feedback of transcription (Hiromi and Gehring, 1987; Goto et al. 1989; Harding et al. 1989). Ectopic $f t z$ expression can transactivate endogenous $f t z$ expression in specific cells (Ish-Horowicz et al. 1989). However, the normal role of such feedback may lie in ensuring persistent expression during germ-band extension to preserve the metameric boundaries that are initially defined by the anterior margins of eve and $f t z$ expression (Lawrence et al. 1987).

The major task is to distinguish direct and indirect interactions between segmentation genes. The initial hierarchy was inferred from mutant cuticular phenotypes and from patterns of segmentation gene expression in mutant embryos. However, the large number of interacting genes makes it difficult to define direct genetic pathways, and has led to studies of ectopic segmentation gene expression using an inducible heat shock promoter to drive generalised segmentation gene expression during the blastoderm stage. Ectopic expression can be induced in precisely staged embryos, allowing immediate responses to be distinguished through their kinetics. In this manner, the effects of generalised $f t z, h$ or hunchback $(h b)$ expression at blastoderm have been explained in terms of direct effects on the expression of other segmentation genes (Struhl, 1985, 1989; Ish-Horowicz and Pinchin, 1987; Ish-Horowicz et al. 1989). For example, ectopic $h$ leads to rapid extinction of $f t z$ expression, consistent with $h$ 's role as a primary repressor of $f t z$ expression (Ish-Horowicz and Pinchin, 1987).

More restricted spatial mis-expression would allow investigations of the finer mechanisms that must underly the precision of final blastoderm pattern, e.g. pair-rule stripe phasing. More precise disruptions could be achieved by using promoters that themselves display spatial regulation, i.e. segmentation gene promoters. Different patterns of mis-expression would arise according to the heterologous promoter chosen.

Previous experiments indicate that such misexpression leads to pattern disruptions and dominant lethality. For example, uncontrolled expression of $f t z, h$ or runt causes pattern defects, indicating that expression in inter-stripe domains is deleterious and causes embryonic lethality (Struhl, 1985; Gergen and Wieschaus, 1986; Ish-Horowicz and Pinchin, 1987; IshHorowicz et al. 1989). Thus, the precise spatial and temporal patterns of segmentation gene expression are crucial in defining the embryonic body plan, and ectopic expression of segmentation gene products can redirect the fates of cells inappropriately expressing these genes.
Nevertheless, several schemes might permit the recovery of flies transformed with predicted dominant-lethal constructs. For example, protein levels could be reduced by depressing translational efficiency. Alternatively, functional expression might be conditional on combining two constructs that are individually viable (e.g. nonsense mutation +tRNA suppressor; inducible promoter + trans-activator - cf. Kakidani and Ptashne, 1988; Webster et al. 1988).

As a preliminary to such experiments, we have generated three gene fusions that express the pair-rule genes, $f t z$, eve and $h$ under the control of a gap-gene promoter $(h b)$. These constructs should drive anterior mis-expression of the pair-rule proteins within the $h b$ domain, the anterior half of the embryo. Such disruptions of segmentation domains should be dominant lethal although the exact effects on pattern will depend on the individual pair-rule gene and the degree of its mis-expression (i.e. the extents to which its endogenous domains overlap that of $h b-$ Fig. 1A).

This paper describes and discusses our unexpected findings that flies transformed with such constructs are viable. We show that the fusion constructs are active and mis-express pair-rule genes in $h b$-like patterns, but that interstripe ectopic expression diminishes when pair-rule genes begin to stripe. These results illustrate the importance of timing in segmentation gene function, and indicate that pair-rule genes have transcriptional control regions downstream of their transcription start sites. We suggest that interstripe $h b-f t z$ expression is repressed by eve. We also describe an unexpected effect of ectopic $h$ expression on sex determination, which illustrates the potential dangers of analysing gene function through gene mis-expression (see also Parkhurst et al. 1990).

\section{Materials and methods}

\section{Fly stocks}

Flies were cultured on yeast, maize meal, molasses, malt extract, agar medium, at $25^{\circ} \mathrm{C}$ unless otherwise stated. The null alleles used in this study are: $D f(2 R) e v e^{I .27}$, cn sca bw $s p / C y O, D f(3 R) 4 S c b / T M 3(f t z)$, and $D f(3 R) h^{i 22}, K i$ roe $p^{p} / T M 3$. The $F G 2 f t z$-lac $Z$ transformant stock expresses a $f t z-l a c Z$ fusion protein that localises in the nucleus ( $Y$. Hiromi, personal communication). The eve-lac $Z$ transformant stock is described in Lawrence et al. (1987).

\section{Constructs}

The $4.7 \mathrm{~kb} B a m \mathrm{HI}-X b a l$ fragment containing the $h b$ promoter and all but 10 bases of the $5^{\prime}$ untranslated leader sequences was subcloned into the blunt-ended Sall site of pUChsneo (Steller and Pirrotta, 1985). This vector, hbneo, drives anterior zygotic expression of coding sequences inserted at unique $B a m \mathrm{HI}$ or $S m a I$ polylinker sites adjacent to the $h b$ promoter. For $h b-f t z$, the AvaIl ( $-75 \mathrm{bp}$ ) to HindIII $(+2.5 \mathrm{~kb})$ genomic fragment including all of the $5^{\prime}$ untranslated leader from pFK1 (Hiromi et al. 1985) was subcloned into the blunt-ended BamHI site of hbneo. For $h b-e v e$, the $4.7 \mathrm{~kb} X$ hoI genomic fragment including all of the 5 'untranslated leader sequences of p48-X4.7 (Macdonald $e t$ al. 1986) was subcloned into the blunt-ended BamHI site of 
$h b n e o$. For $h b-h$, the $6.5 \mathrm{~kb} X b a I$ genomic fragment including 230 bases of $5^{\prime}$ untranslated leader sequences (Rushlow et al. 1989) was subcloned into the blunt-ended BamHI site of hbneo. The appropriate orientation for all clones was determined by restriction analysis.

\section{Embryo analysis}

Embryos were prepared and analysed as described by Wieschaus and Nüsslein-Volhard (1986). Immunohistochemical detection of $h, f t z$, eve, en and $\beta$-gal was performed essentially as described by Macdonald and Struhl (1986), using biotinylated secondary antibodies and avidin-biotinHRP complexes (Vector Laboratories, Inc.). The antibodies used in this study were generously provided by: H. Krause, rabbit anti-ftz antibodies (Krause et al. 1988); M. Frasch, rabbit anti-eve antibodies (Frasch et al. 1987); M. Wilcox, monoclonal anti-en antibodies (Patel et al. 1989); D. Tautz, rabbit anti- $h b$ antibodies (Tautz, 1988); K. Hooper, rabbit anti- $h$ antibodies (Hooper et al. 1989) and H. Durbin, 4C7 monoclonal anti- $\beta$-gal antibodies (Imperial Cancer Research Fund). All secondary antibodies were obtained from Jackson ImmunoResearch Labs (West Grove, PA). The stained embryos were dehydrated in $100 \% \mathrm{ETOH}$ and mounted under a coverslip in methacrylate mounting medium (JB-4, Polysciences) that was polymerised under $\mathrm{CO}_{2}$ for $1-2 \mathrm{~h}$ at room temperature.

\section{In situ hybridisation}

Immunohistochemical whole-mount in situ hybridisation was performed according to the protocol of Tautz and Pfeifle (1989). The probes used for the random priming were: the $4.7 \mathrm{~kb}$ Xhol genomic fragment for eve (p48-X4.7; Macdonald et al. 1986), the $3.5 \mathrm{~kb}$ EcoRI genomic fragment for $\mathrm{ftz}$ (pFK1; Hiromi et al. 1985), and the $1.8 \mathrm{~kb} E c o$ RI cDNA fragment of $h$ (Th $\Delta 1$; Rushlow et al. 1989).

\section{Germline transformation}

$b w$;st embryos were transformed by injection with a mixture of recombinant plasmid $\left(500 \mu \mathrm{g} \mathrm{ml}^{-1}\right)$ and helper plasmid $\left(100 \mu \mathrm{g} \mathrm{ml}^{-1}\right)$, as described by Spradling (1986). The bw;st $\mathrm{G}_{\mathrm{o}}$ adults were outcrossed to wild-type and selected on standard medium supplemented with Geneticin G418 Sulphate (Gibco $-1.5 \mathrm{mg} \mathrm{ml}^{-1}$ but varied according to batch). $\mathrm{G}_{1} b w /+; s t /+$ progeny were mapped by back-crossing crossed to $b w ; s t$ on G418 food. This retested their drug resistance and assigned the insert to a specific chromosome, allowing construction of homozygous or balanced stocks. All neo-resistant transformants were confirmed by Polymerase Chain Reaction (Erlich, 1989) using primers specific to neo portion of the P-element transformation vector.

\section{Assignment of ectopic eve stripes in hb-eve; eve $^{-}$ embryos}

We measured the position (anterior margin) of the ectopically expressed stripes in $h b$-eve; eve embryos and compared them to the endogenous ftz stripe 1 and $e v e$ stripes 1 and 2 in wild-type embryos. Ten embryos were measured for each stripe and the results are expressed below in percentage egg length, where $0 \%$ is the posterior end:

\begin{tabular}{cccc} 
genotype & $\begin{array}{c}\text { eve } \\
\text { stripe } 1\end{array}$ & $\begin{array}{c}f t z \\
\text { stripe 1 }\end{array}$ & $\begin{array}{c}\text { eve } \\
\text { stripe 2 }\end{array}$ \\
\hline$+/+$ & $70.6 \pm 1.4$ & $67.1 \pm 1.4$ & $61.3 \pm 1.5$ \\
hb-eve; eve & $71.2 \pm 1.7$ & & $62.5 \pm 1.3$
\end{tabular}

Thus, the two ectopically expressed $h b$-eve stripes are coincident with the endogenous eve stripes.

\section{Genetic interactions}

We analysed all three fusion gene constructs for dominant interactions (eg., $h b-f t z /+; K r^{-} /+$) with the gap alleles $K r^{l}$, $h b^{P T X I S}$ and $k n i^{I I D 48}$ and for dominant as well as recessive (eg., $h b-f t z /+; h^{-} / h^{-}$) interactions with the pair-rule deletions $D f(2) e v e^{1.27}, D f(3) 4 S c b \quad\left(f t z^{-}\right), D f(3) h^{i 22}$ and $D f(1) r_{n n^{I I B}}$. The only interaction identified was $h b-f t z /+$; $e^{v e} e^{-}++$. (The recessive interaction $\left(h b-f t z /+\right.$; eve $-/ e v e^{-}$) could not be tested due to the lethality of the transheterozygotes.)

\section{Scanning electron microscopy}

Adult males were etherised, mounted on metal discs with double-sided tape, sputter-coated with ionised gold, then viewed with a Phillips 515 scanning electron microscope.

\section{Results}

\section{Flies transformed with hb-pair-rule fusion genes are} viable

We used the $h b$ promoter to examine the effects of misexpressing pair-rule genes in the anterior of the embryo. Three fusion genes - $h b-f t z, h b$-eve, and $h b-h$ - were generated by fusing a $4.7 \mathrm{~kb} h b$ promoter fragment to genomic coding sequences from the $f t z$, eve and $h$ genes (Fig. 1C). The three fusion genes retain most of the $h b$ and pair-rule gene $5^{\prime}$-untranslated leader sequences, while excluding the $5^{\prime}$ flanking sequences of the pair-rule genes that are known to function in striping (Fig. 1C; see Materials and methods). Reporter gene constructs indicate that these $h b$ sequences should be sufficient to mis-express pair-rule genes in the anterior $45 \%$ of the embryo, through about 2 pair-rule stripes (Fig. 1A,B - Driever et al. 1989; Hülskamp et al. 1989). Anterior zygotic $h b$ expression derives from the proximal of two promoters that is first active at stage $11 / 12$, preceding pair-rule expression by about two cleavage-cycles (Fig. 1C - Tautz et al. 1987; Schröder et al. 1988).

The $4.7 \mathrm{~kb} h b$ fragment also includes part of the distal promoter that is first expressed during oogenesis, depositing maternal transcript into the oocyte (Fig. 1A - Tautz et al. 1987; Schröder et al. 1988). This hb promoter is also zygotically active during blastoderm stage 14 in two major stripes, one abutting the anterior zygotic domain, and one in the posterior of the embryo (Fig. 1A,B - Tautz and Pfeifle, 1989). The posterior $h b$ stripe overlaps and extends posterior to $h /$ eve stripes 7 (which share approximately similar phasings). ftz domains are reciprocal to those of eve (Frasch and Levine, 1987) so the posterior $h b$ stripe also overlaps $f t z$ interstripe $6 / 7$. The $4.7 \mathrm{~kb}$ fragment drives maternal expression, but previous experiments have not revealed whether this fragment is sufficient for the posterior stripe expression.

Each of these constructs were introduced into the fly germ-line (see Materials and methods). Unexpectedly, transformed lines were readily recovered for each construct: $10 h b-f t z ; 6 h b-e v e ; 16 h b-h$, indicating that these fusion genes do not give rise to significant degrees 
A hb
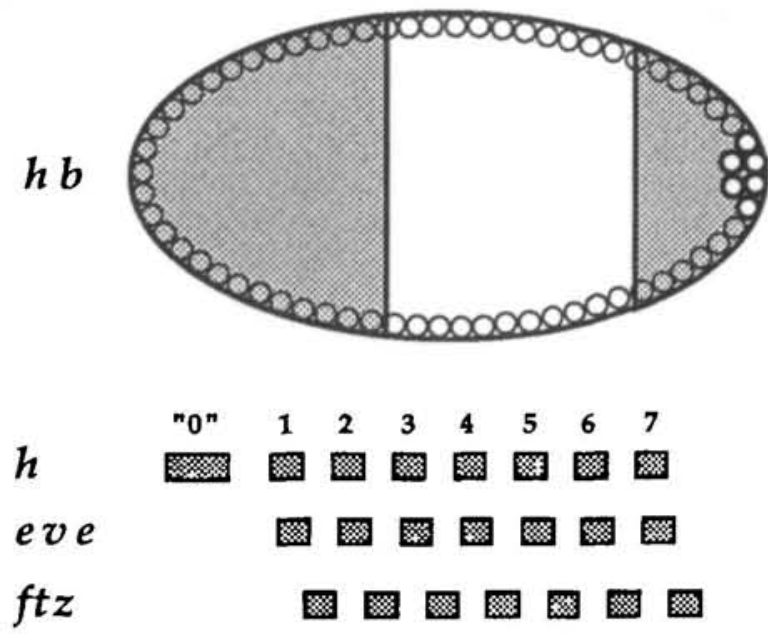

B

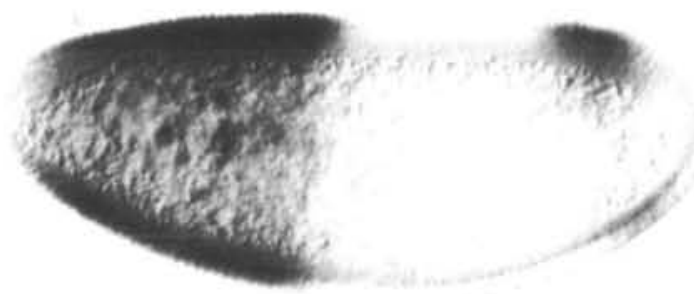

C

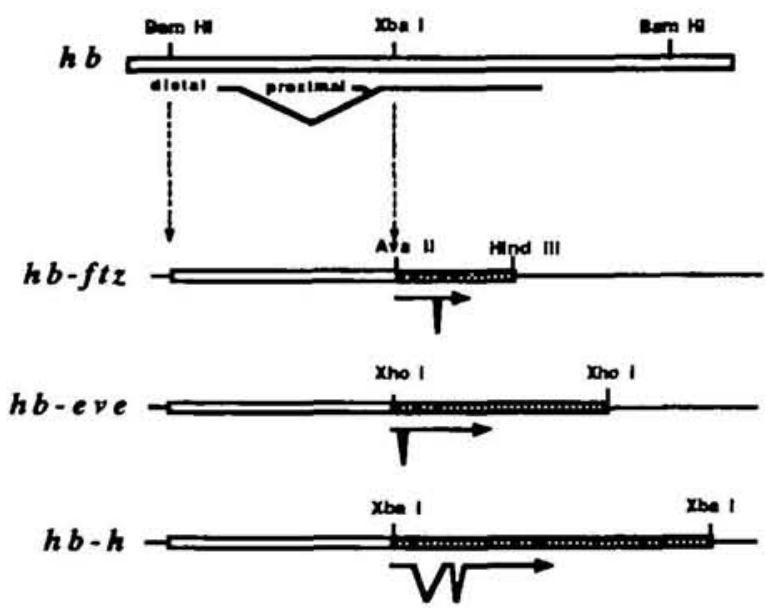

of dominant lethality. The viability of the transgenic flies suggested either that the constructs do not cause pair-rule gene mis-expression (e.g. because of an inactive $h b$ promoter), or that such mis-expression is either tolerated or repressed. We therefore examined expression of the fusion genes and determined the effects of ectopic segmentation gene expression on embryonic pattern.

We shall consider each construct in turn.
Fig. 1. (A) Relative overlap of the $h b$ expression domains with those of $h$, eve and $f t z$. The anterior $h b$ domain includes $h$ /eve stripes 1 and 2 and $f t z$ stripe 1 and part of stripe 2 . The $h b$ posterior domain overlaps and extends posterior to $h /$ eve stripes 7 while overlapping $f t z$ interstripe $6 / 7$. (B) Wild-type expression pattern of $h b$ protein in a late stage 14 embryo. For this and subsequent figures, anterior is to the left, dorsal is uppermost. (C) Restriction map of the $h b$ gene/promoter fragment used and the fusions to $f i z$, eve and $h$. Both the proximal and distal promoters of $h b$ are included in these fusion gene constructs. The restriction sites delimiting the fragments used have been lost in the cloning steps (see Materials and methods).

$\mathrm{ftz}$ is ectopically expressed in $\mathrm{hb}-\mathrm{ftz}$ embryos and partially rescues $\mathrm{ftz}^{-}$larvae

We analysed four independent $h b-f t z$ stocks (in the presence of their endogenous $f t z$ genes) and all show the $h b-f t z$ gene directs ectopic $f t z$ expression. Very weak overall $f t z$ expression is first seen at stages $10 / 11$, before the onset of zygotic $h b$ transcription (Fig. 2A). We have not investigated this phase of $f t z$ protein expression further, but appropriate genetic crosses for $h b$-eve (below) predict that the overall $\mathrm{ftz}$ misexpression is derived from the distal (maternal) $h b$ promoter. Thereafter, $h b-f t z$ embryos express ectopic $f t z$ protein zygotically in the anterior $h b$ domain during nuclear cycle 12 , two cleavage cycles before the endogenous $f t z$ protein is normally seen (Fig. 2B). At the beginning of cycle 14, endogenous $\mathrm{ftz}$ expression begins which is superimposed on the ectopic $h b-f t z$ pattern (Fig. 2C,D). The anterior domain of $h b$ protein expression extends into $\mathrm{ftz}$ stripe 2 (Fig. 2C-E), and the posterior $h b-f t z$ stripe results in continuous $f t z$ expression between stripes 6 and 7 (Figs 1A, 2D,E).

Surprisingly, ftz mis-expression fails to persist through the blastoderm stage, although $h b$ expression is detectable until the onset of gastrulation (Tautz and Pfeifle, 1989). Most ectopic ftz staining decays during blastoderm stage 14 , the time at which endogenous $f t z$ striping becomes prominent (Fig. 2C-F). ftz expression is reduced in interstripe domains (i.e. between stripes $1 / 2$, and $6 / 7$ and anterior of stripe 1 - Fig. $2 E, F)$. By the end of the blastoderm stage, ectopic ftz expression is restricted to a novel stripe, 3-4 cells anterior to $\mathrm{ftz}$ stripe 1 , that does not correspond to a normal $h b$ domain (Fig. 2F).

Most $h b-f t z$ lines are completely homozygous viable and show no significant embryonic cuticular pattern defects (not shown). Nevertheless, $h b-f t z$ encodes an active protein. $\sim 20 \%$ of homozygous $h b-f t z$ adults lack external genitalia that derive from anlagen of segments A8-11 (Schüpbach et al. 1978; Tautz et al. 1987 - Fig. 3A-C). Although the missing structures derive from within the posterior $h b$ stripe domain, we cannot unambiguously demonstrate ectopic $f t z$ expression in this region. The altered pattern in such embryos indicates that the $h b-f t z$ gene encodes functional $f t z$ protein.

Indeed, $h b-f t z$ partially rescues the pattern defects of 
A

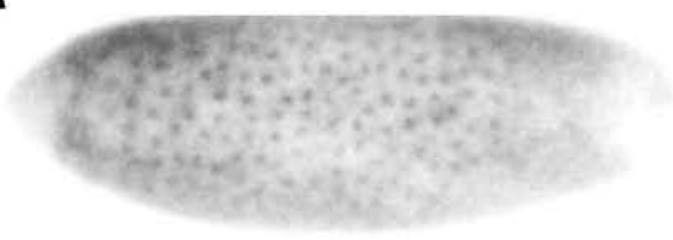

B

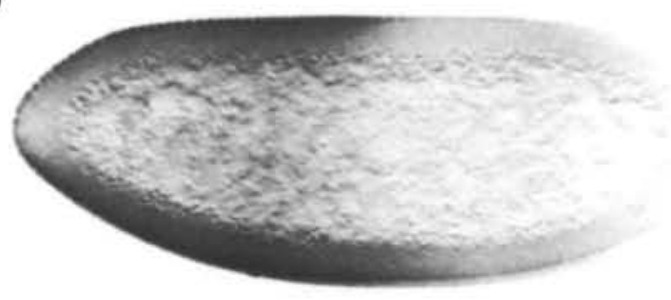

C

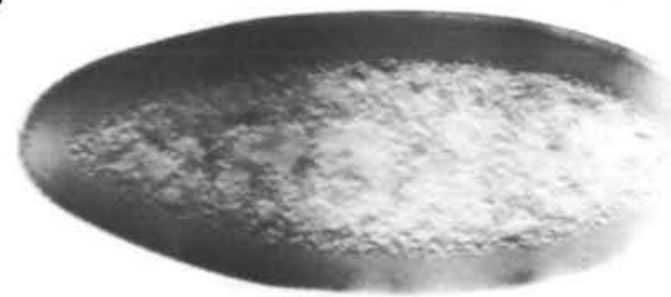

D

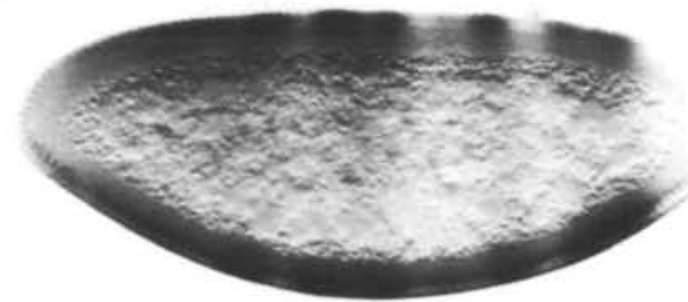

$\mathbf{E}$

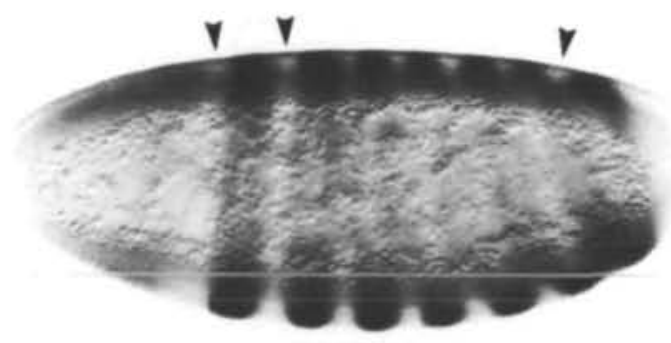

$\mathbf{F}$

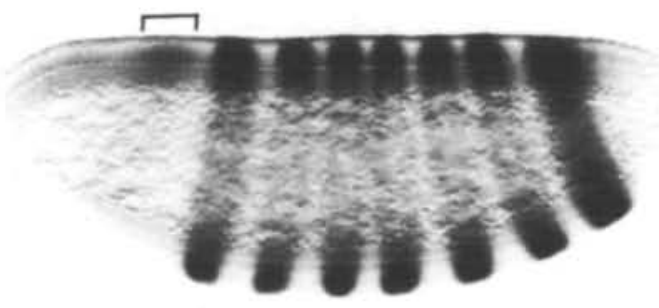

Fig. 2. $f t z$ protein expression in $h b-f t z$ embryos. Embryos containing two copies of the $h b-f t z$ construct in an otherwise wild-type background were stained with an anti$f i z$ antibody (Krause et al. 1988). (A) Stage 10/11 hb-ftz embryo showing ectopic $f t z$ protein in all nuclei, derived from the distal (maternal) $h b$ promoter. (B) Stage 12 embryo showing ectopic $f t z$ protein in the $h b$ domain (anterior half of the embryo). (C-F) Successively older embryos showing the emergence of endogenous $\mathrm{ftz}$ protein stripes in addition to the ectopic expression in the $h b$ domain. As the endogenous fiz stripes begin to resolve, the ectopic expression starts to clear between stripes 6 and 7, stripes 1 and 2, and just anterior of stripe 1 (E; arrowheads). At late stage 14 , the final $f t z$ protein pattern has been achieved, with the removal of all ectopic $f t z$ protein except a small (mostly dorsal) stripe anterior to stripe 1 (F; brackets). For all embryos, anterior is to the left and dorsal is uppermost. The embryo in A is a brightfield photograph of the embryo surface. The embryos shown in B-F were photographed using Nomarski optics.

$f t z^{-}$embryos. The T1 'beard' is restored, as are various chitinised mouthpart structures (Fig. 3E). This implies that the $h b$ promoter is still active during cycle 14 when $f t z$ is needed for patterning. Nevertheless, ectopic $f t z$ is no longer expressed between $f t z$ stripes, indicating that zygotic expression from $h b-f t z$ is negatively regulated in the head and $f t z$ interstripe regions where it would cause pattern defects. The remaining $\mathrm{ftz}$ mis-expression in the head region appears not to cause significant pattern abnormalities.

hb-eve drives ectopic eve expression and causes homozygous lethality

We analysed eve in three transformed lines with autosomal insertion sites and all behave similarly. eve protein expression in $h b$-eve embryos is first detectable as generalised nuclear staining at blastoderm stage 10/11 (Fig. 4A). This protein derives from maternal transcript as it is only seen in embryos from $h b$-eve mothers, but not from wild-type mothers. Such maternal staining is only transitory, soon being replaced by the zygotic $h b$ pattern of expression.

Strong ectopic anterior eve protein expression is first evident at blastoderm stage $12 / 13$, and persists until stage 14 when it overlaps endogenous eve stripes 1 and 2 (Fig. 4B-D). A weak posterior eve stripe is seen during early stage $13 / 14$ (not shown), but its expression is soon masked by the endogenous eve stripe 7. During blastoderm stage $14, h b$-eve expression decays until, by the end of blastoderm, mostly endogenous protein expression exists with very low level ectopic expression in a small anterior cap (Fig. 4D,E). eve is thought to act at the late blastoderm stage to regulate segmentpolarity gene domains and to define the odd-numbered parasegmental boundaries (Lawrence et al. 1987; Ingham et al. 1988). The lack of ectopic eve expression at this stage explains the viability of heterozygous $h b$-eve embryos.

However, all five autosomal $h b$-eve lines are homozygous and trans-heterozygous lethal indicating that two doses of $h b-e v e$ are unconditionally lethal. A 

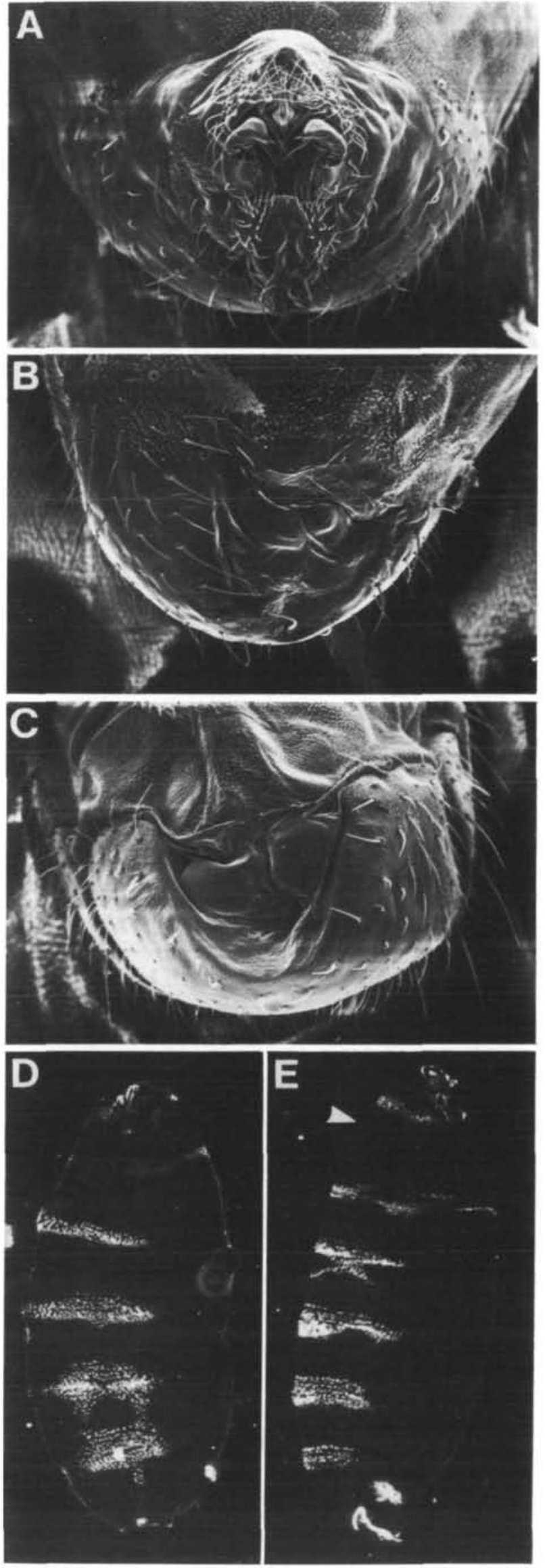

Fig. 3. Posterior defects in $h b-f t z$ flies and partial rescue of $f t z^{-}$larvae by ectopic $f t z$ expression. (A-C) Posterior defects in $h b-f t z$ flies. Scanning electron micrographs of wild-type (A) and $h b-f t z(\mathrm{~B}, \mathrm{C})$ adult male genitalia.

Approximately $20 \%$ of $h b-f t z$ homozygous adults lack posterior structures. While most of the flies with posterior defects include the loss of structures associated with abdominal segments A6-A10 (B), some flies have rudiments of A6 structures (C). Although only males are shown, females are similarly affected. (D,E) Cuticle phenotype of larvae homozygous for $D f(3 R) 4 S c b\left(f t z^{-}\right)$, with zero (D), and two $h b$-ftz copies (E). The latter shows more extensive chitinised mouthparts and the T1-associated ventral hairs ('beard'- arrowhead) is restored. Abdominal segmentation is also somewhat affected although we do not currently understand why the anterior $h b$ promoter affects posterior patterning or why this should only be evident in $f t z^{-}$embryos.

sixth line, in which $h b$-eve is X-linked, is weaker and can be made homozygous. In $h b$-eve balanced stocks, about $25 \%$ (presumably the homozygous embryos) show a consistent cuticular phenotype including fusions of $\mathrm{T} 2 / 3, \mathrm{~A} 1 / 2$ and $\mathrm{A} 3 / 4$, and loss of the $\mathrm{A} 6$ denticle band (Fig. 5A,B). Strikingly, pattern abnormalities arise outside the $h b$ domain where little or no ectopic eve is expressed. These could be due either to nonautonomous action of zygotic eve protein, or to generalised maternal expression from the distal promoter (see Discussion).

$h b$-eve also exerts a weak dominant effect on segmentation and on viability. Most hemizygous (single-copy) $h b$-eve embryos survive, but about $20 \%$ (37/183) die with weak and occasional fusions of adjacent denticle bands (Fig. 5C,D). The frequency and character of the defects is independent of whether the $h b$-eve gene is maternally or paternally inherited, indicating that they are due to zygotic, not maternal, eve mis-expression.

Cross-regulatory interactions among primary pairrule genes indicate that eve regulates the pattern of other pair-rule genes (Ingham and Gergen, 1988) and implies that the $h b$-eve pattern defects may be due to ectopic eve affecting expression of other segmentation genes. We therefore analysed the patterns of $h, f t z$ and en expression in $h b$-eve embryos.

\section{Segmentation gene patterning is disorganised in} hb-eve embryos

$f t z$ and $h$ patterns are indeed affected by $h b$-eve. We analysed embryos from balanced $h b$-eve stocks in which one half of the eggs contain a single $h b$-eve copy and one quarter are homozygous for $h b$-eve. Homozygous $h b$-eve embryos (24/79) show partial or complete fusions of $\mathrm{ftz}$ stripes 3 to 6 (Fig. 5E). Hemizygous embryos show a weaker phenotype in which stripes 3 to 6 are present but compressed (Fig. 5F).

$h b$-eve also disrupts $h$ expression, stripes $1,2,3$ and 7 becoming stronger and broader relative to the other bands (Fig. 5G,H). More strikingly, anterodorsal $h$ expression (stripe ' 0 ' in Fig. 1A) is completely missing 
A
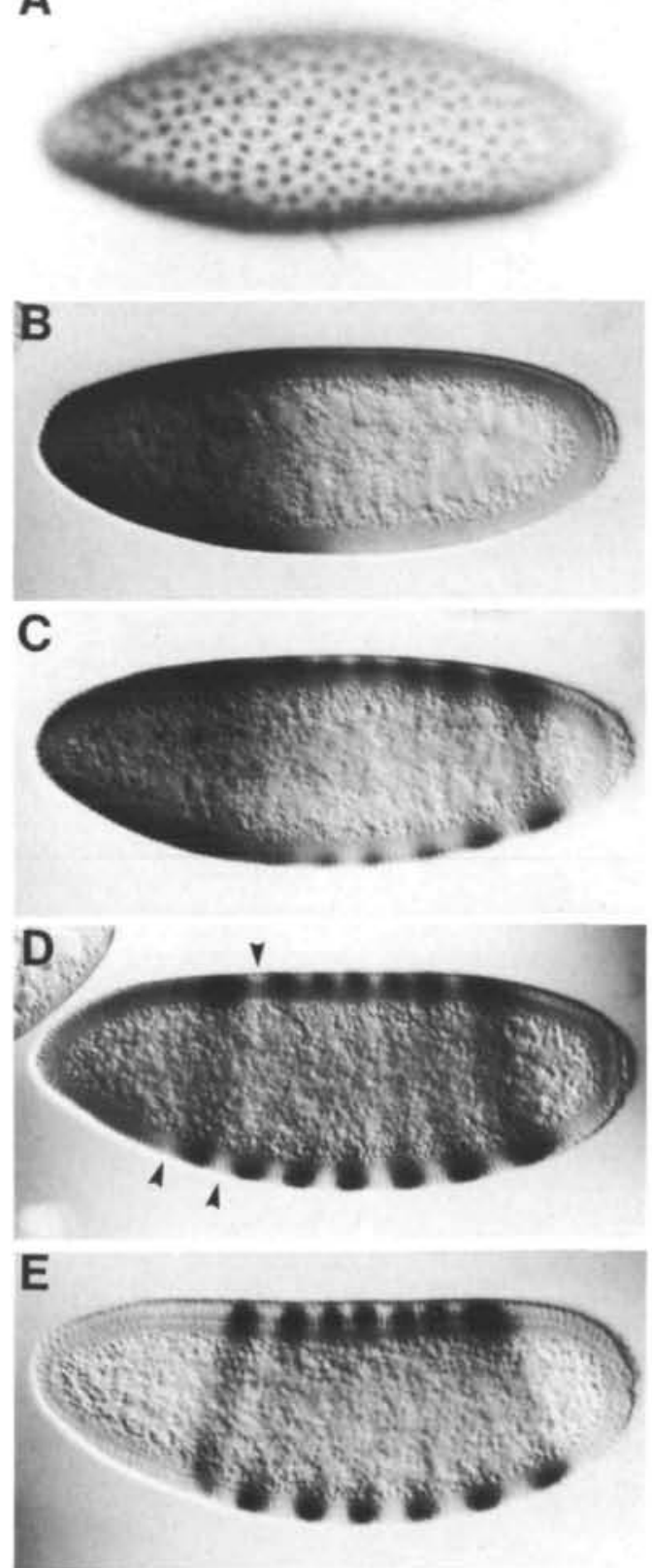

$\mathbf{F}$

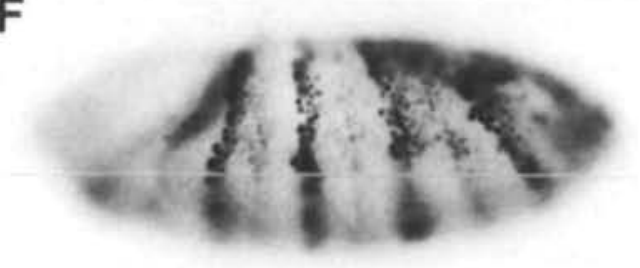

G

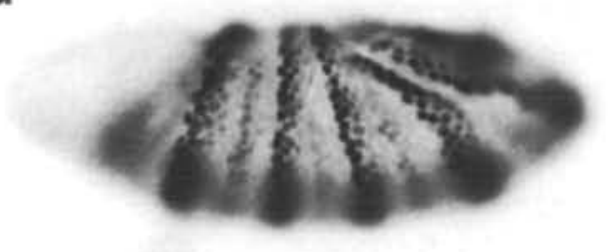

Fig. 4. eve protein expression in $h b$-eve embryos. Embryos from a balanced $h b$-eve stock in an otherwise wild-type background were stained with anti-eve antibodies (Frasch $e t$ al. 1987). (A) Stage 10/11 hb-eve embryo showing eve protein in all nuclei derived from the distal (maternal) $h b$ promoter. (B) Stage 12/13 embryo showing ectopic eve protein in the $h b$ domain (anterior half of the embryo). (C) Slightly older embryo showing the emergence of endogenous eve protein stripes in addition to the ectopic expression in the $h b$ domain. (D) As the endogenous eve stripes begin to resolve, the ectopic expression starts to clear between stripes 1 and 2, and just anterior of stripe 1 (arrowheads). (E) At late stage 14, the final eve protein pattern has been achieved, with the removal of all ectopic eve protein except very low-level anterior expression not visible in the photograph. $(F, G)$ During germ-band extension, eve protein stripes are disrupted in $h b$-eve containing embryos (F) compared to their wild-type siblings $(\mathrm{G})$. The embryos in $\mathrm{A}, \mathrm{F}-\mathrm{G}$ are bright-field photographs of the embryo surface. The embryos shown in B-E were photographed using Nomarski optics.

in $35 \%(21 / 60)$ of these embryos. This suggests that the ectopic eve suppresses the regionalised activation of $h$ stripe $0 . h$ stripes 1 and 2 are not eliminated, indicating that eve is interfering with regional signals specific for stripe 0 . The cis-regulatory region for $h$ stripe 0 has not yet been characterised, but may be responding directly to elevated levels of bicoid and/or dorsal morphogens (Driever and Nüsslein-Volhard, 1988b; Steward et al. 1988).

Initial metameric patterning is roughly normal in $h b$-eve as judged by the earliest pattern of en expression (not shown). However, eve expression at gastrulation, which should be similar to that of en, is somewhat abnormal in homozygous $h b$-eve embryos. $25 \%$ of $h b$-eve embryos, show 14 eve stripes whose domains appear correctly positioned but whose anterior margins (which parallel those of en) appear less well defined (Fig. 4E,F). eve expression is also weaker than wild-type. This altered pattern is found in all three lines examined as well as in trans-heterozygous lines containing two different $h b$-eve copies.

Drastic effects on metameric patterning become apparent about $1 \mathrm{~h}$ later when some embryos begin to show low-level en expression in all cells. By $6-7$ h postfertilisation, the generalised en expression becomes stronger and seen in $37 \%(41 / 112)$ of embryos (Fig. 5I). In some embryos, the endogenous en stripes are still visible above the generalised expression and are disorganised in about half such embryos (Fig. 5J). Thus, the pattern defects in homozygous $h b$-eve embryos are due to an inability to maintain metameric subdivisions.

hb-h embryos show normal segmentation but aberrant sex determination

Fig. 6A shows ectopic expression of $h$ in the anterior region of $h b-h$ embryos at about nuclear cycle 12 . This expression begins to clear during early cycle 14 (Fig. 6B-D), although the $h b$ promoter remains active in a stripe of cells anterior to stripe 1 (Fig. $6 \mathrm{E}$ ). $h b-h$ 

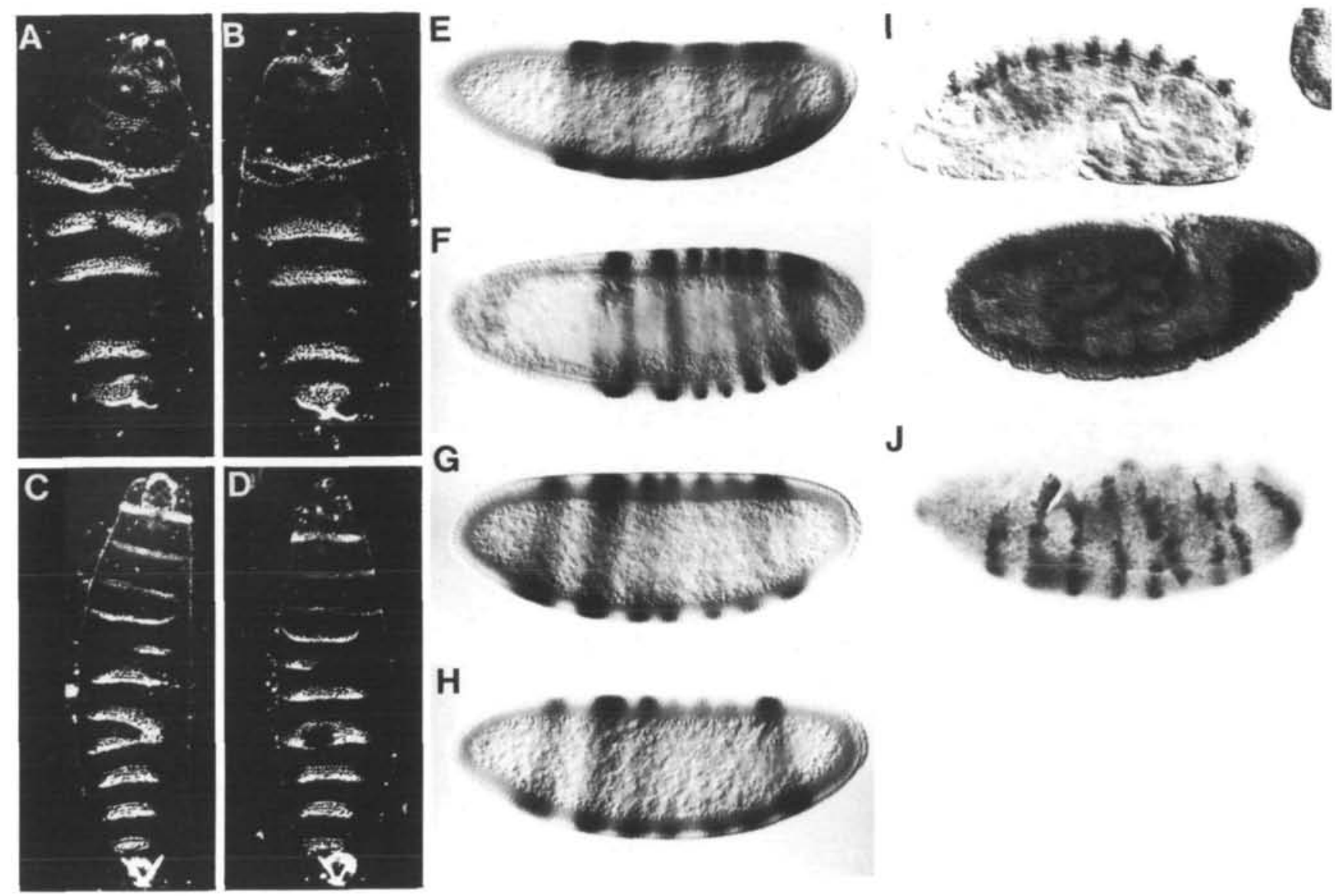

G

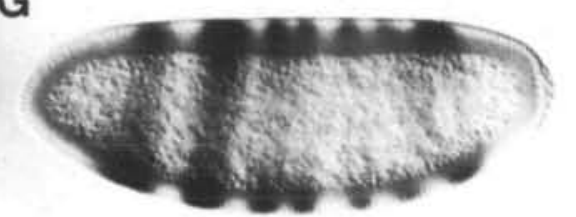

J

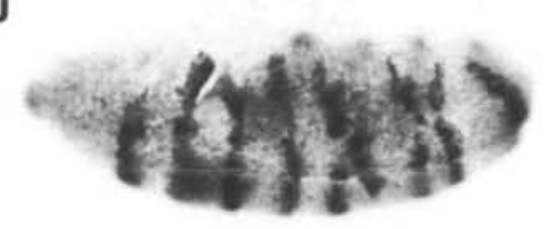

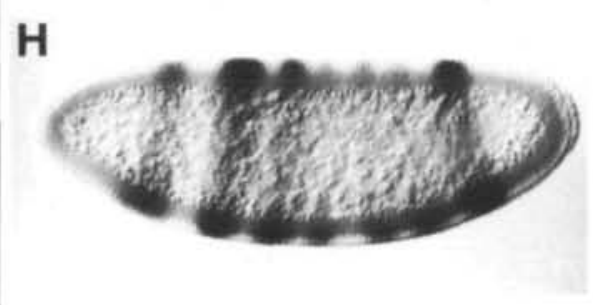

Fig. 5. $h b$-eve containing embryos have pattern defects and disrupted segmentation gene expression. (A,B) Severe cuticular phenotypes of homozygous hb-eve larvae. A6 is mostly missing while A1/A2 and A3/A4 are fused. (C,D) The cuticular phenotypes of hemizygous $h b$-eve embryos, showing loss/fusion of segments most commonly involving A2, A4-5. $(\mathrm{E}, \mathrm{F}) h b$-eve embryos stained with anti-ftz antibodies. (E) Homozygous $h b$-eve embryo showing fused ftz stripes. This pattern is not seen in crosses that yield only hemizygous $h b$-eve embryos. (F) Hemizygous hb-eve embryo showing compressed $f t z$ stripes 3 to 6 . (G,H) hb-eve embryos stained with anti-h antibodies. The anterodorsal headpatch ('stripe 0') is absent with a anterior shifting and broadening of stripes 1 and 2 . The embryos in $\mathrm{E}-\mathrm{H}$ were photographed with Nomarski optics. (I) en expression in hb-eve embryos, stained with anti-en antibodies (Patel et al. 1989). Two similarly staged embryos from a balanced $h b$-eve stock, are shown in the same optic field. Compare the upper embryo (with normal en staining) to the lower embryo showing the generalised en expression that is seen only in crosses yielding homozygous $h b$-eve embryos. (J) In some embryos, disorganised endogenous en stripes can still be visualised above the generalised expression. (Weaker photographic exposure than I to reveal the en stripes).

embryos show no obvious segmentation defects, consistent with the cessation of ectopic $h$ expression before it would inhibit $f t z$ expression. Ectopic $h$ expression in a $h^{-}$background partially rescues $h$ pattern defects in the anterior of the embryo, indicating that $h b-h$ is active while metameric pattern is being established. Mouthparts become more organised, and anterior structures including the maxillary sense organs and T1 denticle band are restored (Fig. 6G).

Unexpectedly, $h b-h$ interferes with sex determination, a process in which $h$ does not normally function. $h b-h$ males are fully viable and fertile whereas more than $99 \%$ of $h b-h$ females die as embryos whose head defects correlate with the domain of $h$ mis-expression. See Parkhurst et al. (1990) for a detailed examination and explanation of this phenotype.
Fusion gene transcripts are regulated in the interstripes The above results show that homozygous $h b-f t z, h b-h$ and most hemizygous $h b-e v e$ transformants can tolerate early ectopic expression of the respective pair-rule gene, but that later expression does not lead to pattern defects. This is not merely due to lack of promoter activity as $h b-f t z$ and $h b-h$ partially rescue embryos lacking endogenous $f t z$ and $h$, respectively. (The variable $h b$-eve cuticular phenotype prevents unambiguous identification and analysis of $h b-e v e$; eve embryos.) Rather, interstripe expression is eliminated before it can affect pattern, either by regulation of transcript levels or by inhibition of translation of the hybrid mRNAs.

We excluded the latter explanation by showing that transcript patterns mirror those of the mis-expressed 


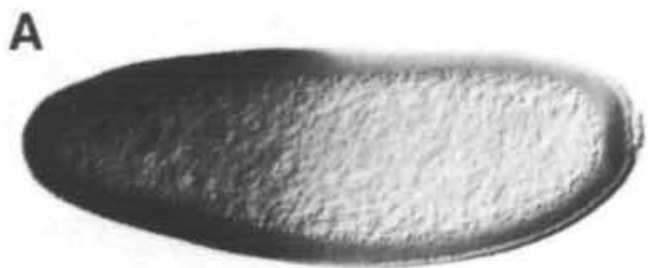

B

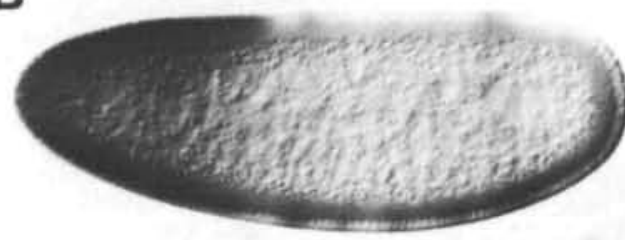

C

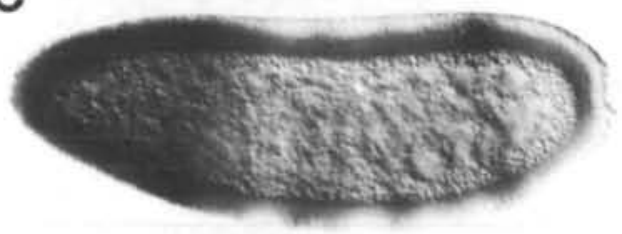

D
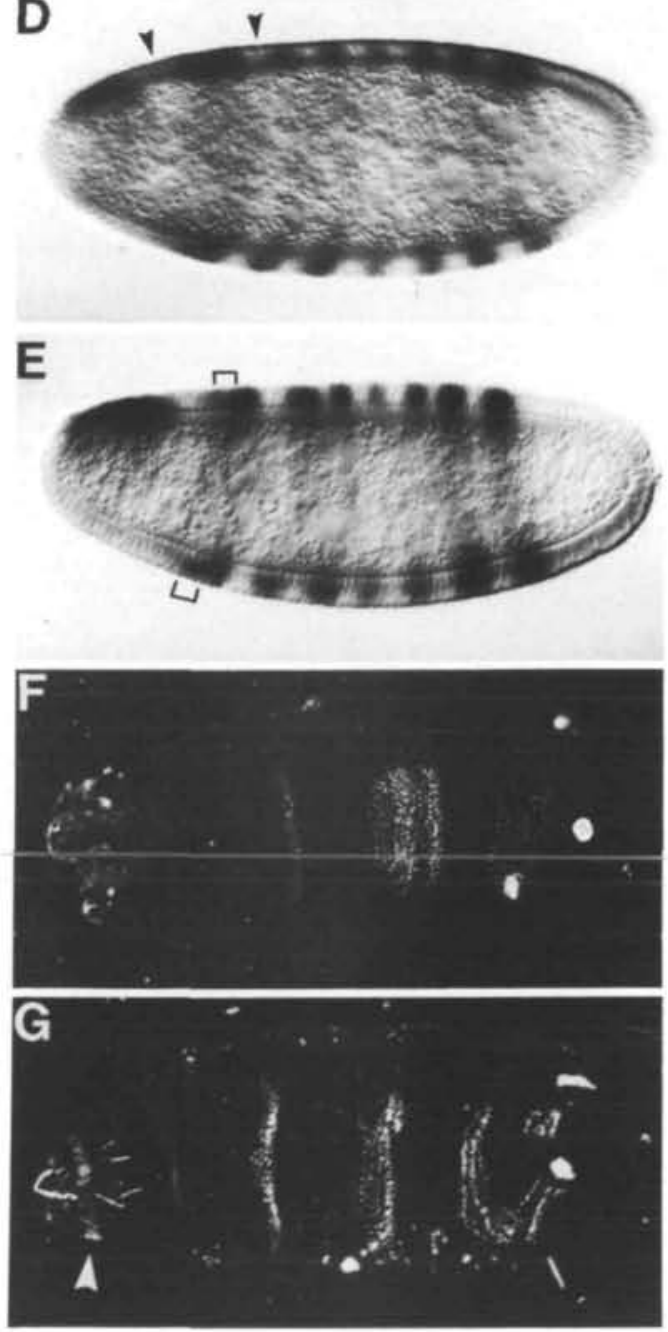

Fig. 6. $h$ protein expression in $h b-h$ embryos and partial rescue of $h^{-}$larvae by the ectopic $h$ expression. (A) Stage 12 embryo showing ectopic $h$ protein expression in the $h b$ domain (anterior half of the embryo). (B-D) Successively older embryos showing the emergence of endogenous $h$ protein stripes in addition to the ectopic expression in the $h b$ domain. As the endogenous $h$ stripes begin to resolve, the ectopic expression starts to clear between stripes 1 and 2 , and just anterior of stripe 1 (D; arrowhead). At late stage 14 , the final $h$ protein pattern has been achieved, with the removal of all ectopic $h$ protein except a small stripe adjacent to stripe 1 ( $\mathrm{E}$; brackets). All embryos contain one copy of the $h b-h$ construct in an otherwise wild-type background, and were photographed using Nomarski optics. $(\mathrm{F}, \mathrm{G}) h b-h$ partially restores pattern to $h^{-}$larvae. Cuticle phenotype of homozygous $D f(3 R) h^{i 22}$ larvae, (F) lacking $h b-h$, and (G) including one copy of $h b-h$. Mouthparts, as well as the T1 denticle band are restored (G; arrowhead).

pair-rule protein. In $h b-f t z$ embryos, $f t z$ transcripts initially accumulate in the anterior half of the embryo, but are then repressed between the normal stripes, leaving only a band of ectopic transcripts anterior to $\mathrm{ftz}$ stripe 1 (Fig. 7A-D). eve and $h$ transcription in $h b-e v e$ and $h b-h$ embryos, respectively, mimic the patterns of protein accumulation (Fig. 7E-L), showing that negative regulation of interstripe expression from the $h b$ fusion genes is transcriptionally/post-transcriptionally (but not translationally) regulated. The different expression patterns of the three fusion genes shows that the regulation must act through pair-rule sequences present in the fusion constructs.

$\mathrm{hb}-\mathrm{ftz}$ and $\mathrm{hb}-\mathrm{eve}$ retain negative regulatory elements and their expression does not require autoactivation

Analysis of the $h b-f t z ; f t z^{-}$and $h b-e v e ; ~ e v e^{-}$embryos also show that the fusion gene constructs retain control sequences that repress their expression in the interstripe regions. We find that the initial fusion-genestaining patterns are not altered in $f t z^{-}$or eve $e^{-}$mutant embryos. All stage 13 embryos in a balanced $h b-f t z$; $f t z^{-}$stock show high-level anterior $f t z$ expression, including the $25 \%$ of embryos that must lack endogenous $f t z$ activity (not shown). Similarly, all embryos from a balanced $h b-e v e ; e v e^{-}$stock, including those lacking an endogenous eve gene, show ectopic anterior eve expression that can only derive from the $h b$-eve fusion gene. During blastoderm stage $14, h b-e v e ; \varepsilon v e^{-}$ embryos are distinguished by their lack of endogenous striped expression. Such embryos still express eve in the anterior $h b$ domain except within two domains that correspond in position to the two overlapping eve interstripes - anterior to stripe 1 and between stripes 1 and 2 (Fig. 8A,B; see Materials and methods). By the late blastoderm stage, $h b$ transcripts from the distal $h b$ promoter accumulate in two anterior stripes, the more posterior of which corresponds to $f t z$ stripe 1 (Tautz and Pfeifle, 1989); however, these expression domains do not overlap with those of eve ectopic expression in $h b-e v e ; e v e^{-}$embryos. Thus, the control elements 
A

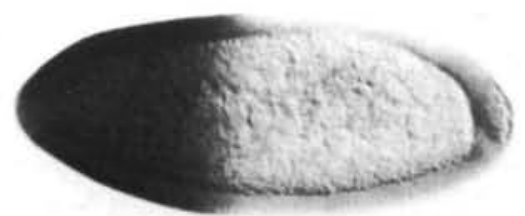

B

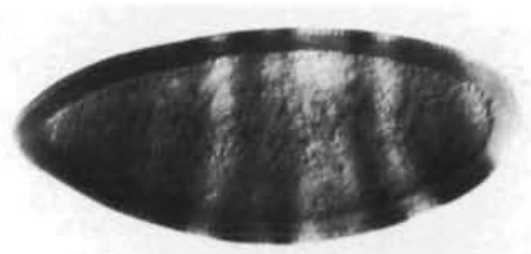

C

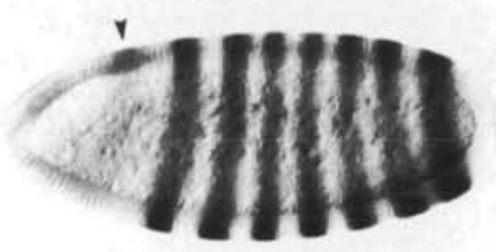

D

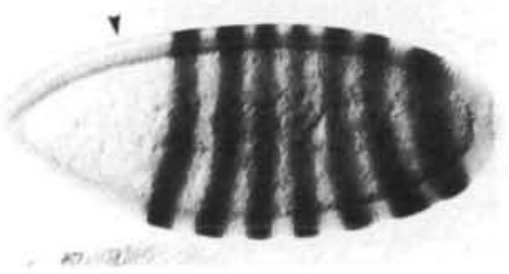

E

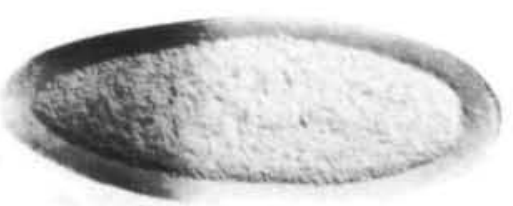

$\mathbf{F}$

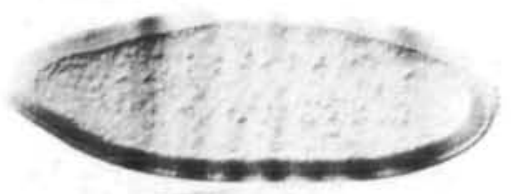

G

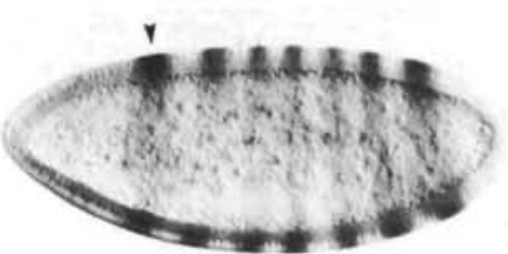

H

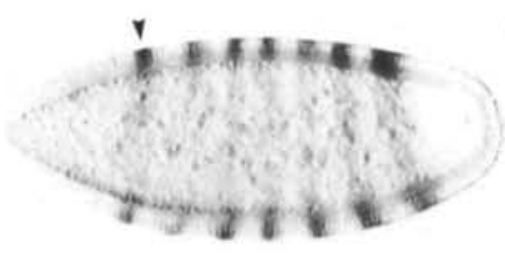

I

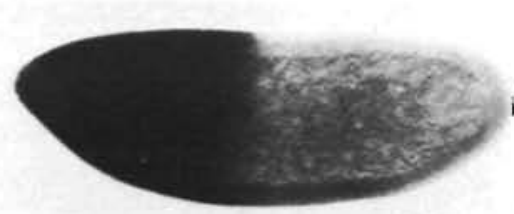

J

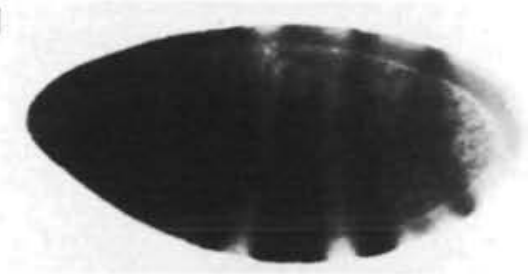

K

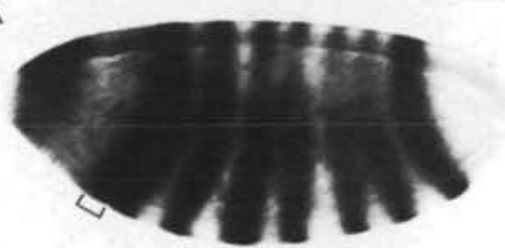

$\mathbf{L}$

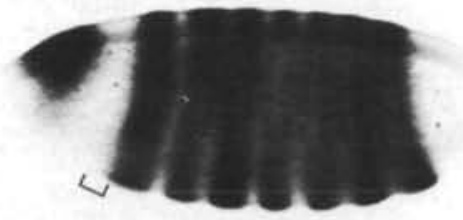

Fig. 7. Interstripe expression of fusion genes is transcriptionally regulated. $h b-f t z, h b-e v e$ and $h b-h$ - containing embryos were analysed by whole-mount in situ hybridisation with probes specific for $f t z$, eve and $h$, respectively. The ectopic transcripts mimic the protein expression pattern and are lacking in the respective interstripe regions. (A-C) Successively older $h b-f t z$ embryos hybridised with $f t z$ sequences. At the peak of $f t z$ expression $(C)$, all ectopic expression has been cleared away except for a small (mostly dorsal) stripe just anterior of stripe 1 (arrow) when compared to a wild-type embryo at the same developmental stage (D). (E-G) Successively older $h b$-eve embryos hybridised with eve sequences. At the peak of eve expression (G), all ectopic expression has been cleared away except for a small stripe adjacent to stripe 1 (arrow) when compared to a wild-type embryo at the same developmental stage $(\mathrm{H})$. Very low-level expression persists in the head region. (I-K) Successively older $h b-h$ embryos hybridised with $h$ sequences. At the peak of $h$ expression (K), ectopic expression has been cleared away except for a stripe adjacent to stripe 1 (bracket) when compared to a wild-type embryo at the same developmental stage (L). All embryos were photographed using Nomarski optics.

mediating such negative control must exist within the eve sequences included in the $h b-e v e$ construct.

It is more difficult to visualise interstripe repression of $h b-f t z$, as endogenous $f t z$ domains overlap domains of late zygotic $h b$ expression. However, the interaction between $h b-f t z$ and eve suggests that $f t z$ also retains a repressor element that imposes its negative control on the $h b$ promoter (see below). $h b-h$ may also retain downstream negative regulatory elements that clear ectopic $h$ expression between $h$ stripes 1 and 2, but the female lethality of $h b-h$ embryos has prevented our demonstrating this directly.

Generalised $f t z$ expression from the inducible heatshock promoter causes pattern defects by autoregulatory activation of the chromosomal ftz gene (Hiromi and Gehring, 1987; Ish-Horowicz et al. 1989). Similarly, eve can autoregulate its own expression (Harding et al.
1989). However, initial fusion-gene-staining patterns are not altered in $\mathrm{ftz}^{-}$or eve mutant embryos, suggesting that $h b-f t z$ and $h b-e v e$ are independent of endogenous $f t z$ or eve activity. We confirmed this by using lac $Z$ fusions to the $f t z$ and eve promoters to monitor endogenous promoter activities (Hiromi et al. 1985; Lawrence et al. 1987). hb-ftz; ftz-lacZ embryos display no ectopic lac $Z$ expression (not shown), indicating that endogenous $\mathrm{ftz}$ transcription is not autoactivated by the $h b$-encoded ectopic $f t z$ protein. Similar results are obtained using $h b-e v e$ and a eve-lac $Z$ fusion gene (not shown). Thus, $h b-f t z$ and $h b-e v e$ ectopic expression do not autoactivate endogenous expression. The female lethality associated with the $h b-h$ construct precludes our analysis of $h b-h ; h^{-}$ embryos, but the $h$ gene appears not to be autoregulated (Hooper et al. 1989). 

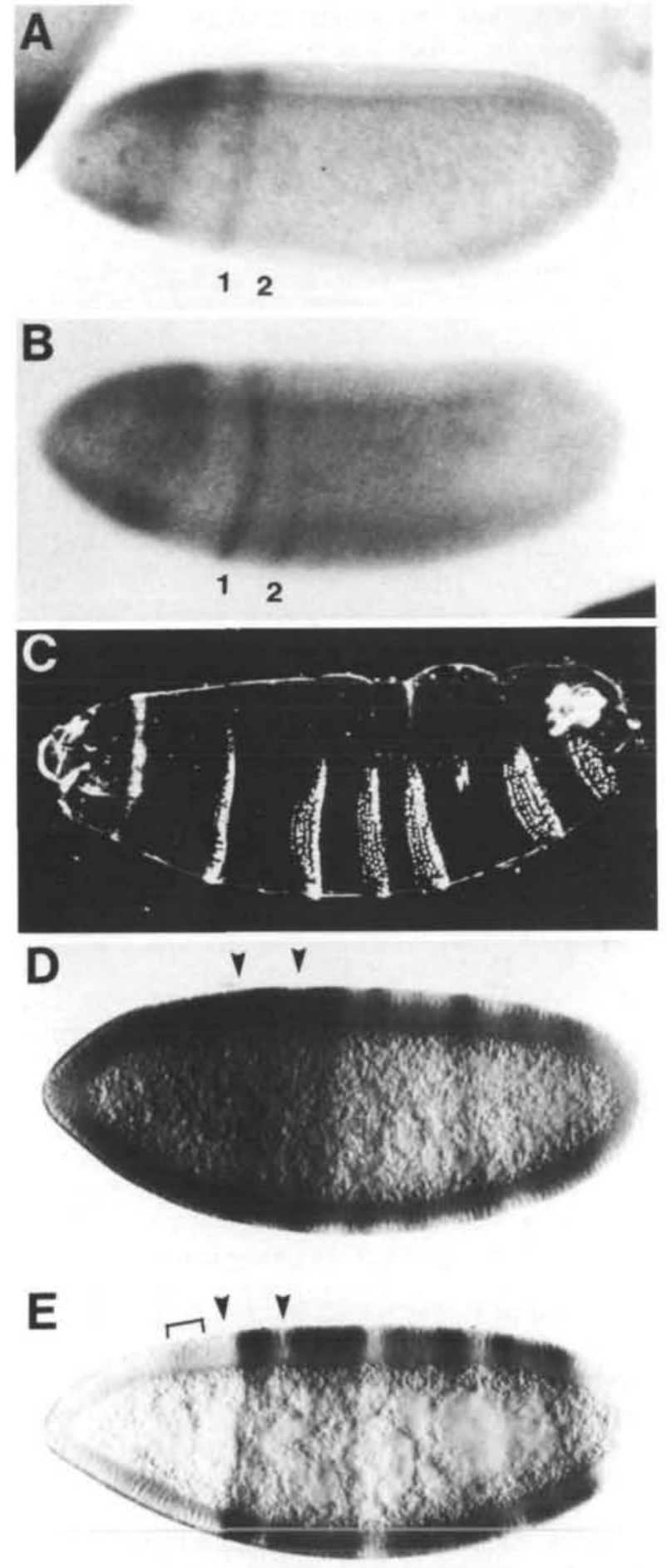

eve negatively regulates $\mathrm{hb}-\mathrm{ftz}$

As interstripe repression is likely to be mediated by other segmentation genes, we analysed phenotypic interactions between the fusion genes and gap or pairrule mutations, hoping to identify such repressors. Although most mutant combinations show no dominant interactions, $h b-f t z$ and eve trans-heterozygotes ( $h b-$ $\mathrm{ftz} /+$; eve $-/+)$ are lethal (0/187 adult progeny), dying as embryos with substantial pattern defects (Fig. 8C).
Fig. 8. Fusion gene constructs retain negative regulatory elements. (A,B) Late stage $14 \mathrm{hb}-\mathrm{eve}$; eve $\mathrm{e}^{-}$embryos stained with anti-eve antibodies. Initial interstripe eve expression is repressed leaving ectopic protein expression in the normal eve stripes 1 and 2 positions (see Materials and methods for measurements) and in a cap at the anterior. (C-D) eve negatively regulates $h b-f t z$.

(C) Cuticle pattern defects in $h b-f t z /+; e v e^{-} /+$transheterozygous embryos affecting T3, A2, A6. hb-ftz; eve trans-heterozygous embryos stained with anti-ftz antibodies show that the ectopic $f t z$ expression is no longer removed from the $f t z$ interstripe regions (D; arrowheads). (E) $h$ does not regulate interstripe $h b-f t z$ expression. $f t z$ ectopic expression is still repressed in $h b-f t z ; h^{-}$embryos (arrowheads) at the same time as $h b-f t z$ drives ectopic anterior dorsal $f t z$ expression (brackets).

Fig. 8D shows that interstripe $f t z$ expression persists in $h b-f t z /+; e v e^{-} /+$embryos, suggesting that eve is responsible for repressing such interstripe expression.

In contrast, $h b-f t z$ shows no dominant interactions with $h$, the other well-characterised $f t z$ repressor, either because $h b-f t z$ is $h$-independent, or because $50 \%$ of wild-type $h$ levels is sufficient to regulate $h b-f t z$. We favour the former explanation as anterior $f t z$ expression is still regulated in embryos that completely lack $h$. ftz expression is still repressed anterior to stripe 1 and between stripes 1 and 2 in $h b-f t z ; h^{-}$embryos, suggesting that $h$ does not regulate $h b-f t z$ (Fig. 8E), although the broadened endogenous $f t z$ expression in $h^{-}$embryos (Carroll and Scott, 1986; Howard and Ingham, 1986; Hiromi and Gehring, 1987) precludes detection of low-level interstripe expression. This indicates that eve is likely to be a major repressor of $f t z$ expression.

\section{Discussion}

The fusion genes retain downstream transcriptional control elements

In this paper, we show that ectopic expression of $f t z, h$ or eve under the control of the $h b$ promoter does not necessarily result in pattern defects. Embryos containing the $h b$ fusion genes initially express pair-rule genes in the anterior $h b$ domain, but such ectopic expression largely ceases during blastoderm stage 14 (Figs 2, 4, 6). This is partially due to a decline in activity of the proximal $h b$ promoter, as well as to its regulation by residual pair-rule sequences. Several lines of evidence demonstrate that the $h b$ promoter in these fusion genes is still active at the time of pair-rule gene function and is regulated in the head and interstripe regions. First, the fusion gene constructs partially rescue the mutant pairrule phenotype (Figs $3 \mathrm{~B}$ and $6 \mathrm{G}$ ). Second, at blastoderm stage 14, there are ectopic stripes of eve in a $h b-e v e ;$ eve $e^{-}$background that overlap the positions of the endogenous eve stripes (Fig. 8A,B). Third, although the same promoter is used for all three fusion gene constructs, each is expressed ectopically in head domains that differ between constructs (Figs 2F, 4E, 6E and $7 C, G, K)$. Finally, interstripe expression is no 
longer regulated in $h b-f t z /+$; eve/t embryos (Fig. 8D), and persists through the time of pair-rule gene expression.

For all three fusion genes, the patterns of transcript and protein localisation are similar, indicating that the lack of interstripe expression is not due to a failure of translation (Fig. 7). Clearing of interstripe transcripts through their differential stability is also unlikely as segmentation gene transcripts are extremely unstable (Edgar et al. 1986, 1989). Although post-transcriptional mechanisms cannot be excluded, lack of interstripe transcripts is most likely due to repression of interstripe transcriptional initiation.

The most likely candidate for a ftz interstripe repressor is eve. The lethality of $h b-f t z /+$; eve ++ embryos shows that reduced eve levels exaggerate the effects of ectopic $f t z$ expression, i.e. that eve normally acts to inhibit $f t z$. This is consistent with previous suggestions that eve repression defines the anterior boundaries of each ftz stripe (Ish-Horowicz et al. 1989), and would be mediated, at least in part, through downstream eve-responsive elements. In contrast, $h b-f t z$ shows no interactions with $h$, the other characterised $f t z$ repressor. $h b-f t z$ expression is repressed between $f t z$ stripes 1 and 2 , even in $h b-f t z$ embryos lacking $h$ (Fig. 8E), suggesting that $h$ does not act on $h b-f t z$ and that $h$ regulation of $f t z$ striping might operate through upstream $f t z$ sequences.

We do not know which genes repress eve and $h$ expression in $h b-e v e$ and $h b-h$. The best candidate is the runt pair-rule gene whose stripe domains are roughly complementary to those of eve and $h$ (Gergen and Butler, 1988; Ingham and Gergen, 1988). Although there is no direct evidence for such regulation, we consider it more likely that the downstream control regions react to a single pair-rule regulator than to alternative combinations of differing gap-genes.

\section{Timing requirements for segmentation gene function}

The timing of pair-rule gene expression is crucial: embryos are unaffected by generalised anterior misexpression during blastoderm stages 10 to 13 . Only late in cleavage cycle 14 do the pair-rule genes act to regulate segment-polarity gene expression and metameric pattern, by which stage expression from the fusion genes is restricted to functionally irrelevant domains.

Further indications of the importance of timing in patterning the early embryo comes from the temporal specificity of pair-rule autoregulation. Neither $h b-f t z$ nor $h b$-eve autoactivate their endogenous genes, despite the presence of autoregulatory elements within each promoter. In contrast, late blastoderm and early gastrula-staged embryos are susceptible to fiz autocatalytic activation (Struhl, 1985; Ish-Horowicz et al. 1989). Autoregulation appears to be important for persistent expression during gastrulation and germ-band extension, but not during the earlier phases when pair-rule domains are being established (in contrast to reactiondiffusion models for pair-rule striping - Meinhardt, 1982). We note that $h$ is not autoregulated and that its expression decays immediately following blastoderm (Hooper et al. 1989).

\section{Pattern defects caused by ectopic pair-rule expression}

Although all three constructs are viable, each has specific effects on development.

$\mathrm{hb}-\mathrm{ftz}$

Homozygous $h b-f t z$ embryos show no obvious embryonic cuticular defects, but a proportion of adult flies lack terminal structures. The exact basis for this pattern abnormality is unclear, although it might be due to a weakly expressed posterior stripe of ectopic ftz expression, which extends into the A8-11 genital primordia. Only occasional cells can be affected as most adults are viable and the embryonic en pattern appears normal.

\section{hb-eve}

Unlike the other two constructs, $h b$-eve causes significant pattern abnormalities, with two copies being almost completely lethal and leading to metameric instability and subsequent segmentation defects. eve stripes during gastrulation are weak and irregular, and a high proportion of older $h b$-eve embryos display a generalised pattern of en expression in which clear en boundaries are lacking (Fig. 5I). Nevertheless, $h b$-eve embryos retain considerable metameric organisation (Fig. 5A,B), indicating that parasegmental boundaries can be maintained even in the absence of clear en boundaries. We presume that metamerisation initially requires en stripes, but thereafter other segmentpolarity genes can contribute to intrasegmental patterning.

The major surprise is that the pattern abnormalities in homozygous $h b$-eve embryos are not restricted to the $h b$ domain, i.e. to the domain of eve mis-expression. Thus, eve stripes at gastrulation are disrupted throughout the embryo (Fig. 4F; see also Fig. 5A,B). Such nonautonomy is unexpected as eve encodes a nuclear homoeobox protein whose direct actions should be local, i.e. restricted to the $h b$ domain. Such defects are seen (albeit rarely and more weakly) in heterozygous embryos (even when from wild-type mothers), indicating that they are due to zygotic expression, presumably in the posterior domain. Although we do not directly detect such expression, we note that the domains of gap-gene action extend into domains where protein levels are immunologically undetectable (Gaul and Jäckle, 1989; Pankratz et al. 1989, 1990; Stanojevic et al. 1989; Hülskamp et al. 1990).

$\mathrm{hb}-\mathrm{h}$

Although $h b-h$ causes female lethality by interfering with sex determination (Parkhurst et al. 1990), the viability of $h b-h$ males shows that the ectopic $h$ does not cause segmentation defects (even in two doses, unpublished observations). This is unexpected as $h$ and eve are both primary pair-rule genes that can affect each others patterning (Ingham and Gergen, 1988). Indeed, $h b-e v e$ affects $h$ patterning, although eve pattern is 
normal in $h b-h$ embryos. This may indicate that $h$ 's role in embryonic patterning is subsidiary to that of eve. Alternatively, the embryo could be less sensitive to ectopic $h$ because $h$ 's targets are under more redundant control (see below).

\section{Redundancy}

Previous experiments have demonstrated roles for upstream sequences in regulating pair-rule striping. The $f t z$ zebra element is able to direct striped expression of reporter genes, albeit predominantly in the mesoderm (Hiromi and Gehring, 1987), and putative negative regulatory elements have been defined within this region, including potential eve binding sites (Dearolf $e t$ al. 1989b).

$h$ and eve striping appear to be regulated differently from $f t z$. Upstream domains appear to control specific individual stripes, presumably by sensing regionalised spatial cues (e.g. gap genes; Howard et al. 1988; Struhl, 1988). Upstream $h$ elements can confer striped expression on a reporter gene construct, indicating that they include both positive and negative elements (Pankratz et al. 1990; G. Riddihough and M. Lardelli, personal communication). Our experiments indicate that there are also repressor sites downstream of the transcription start, i.e. that stripe repression is under redundant control. A likely reason for redundant control is to achieve the necessary precision of striping to allow precise phasing between different pair-rule genes. $h$ and eve show similar stripe domains except that each $h$ stripe is 1-2 cells anterior of each eve stripe (Carroll et al. 1988). Such displaced phasings could arise because $h$ and eve sense similar positional cues, but with slightly differing affinities for their signals. Such striping would involve upstream repressor elements acted upon by gap genes proteins. The final stripe phasings would be achieved by the action of other pair-rule genes acting, at least in part, through downstream elements. Our analysis of $h$ striping patterns in embryos mutant for other segmentation mutations has suggested that both mechanisms may operate, i.e. that the control is redundant (Hooper et al. 1989). Such redundancy might be required to define stripes with precise phase relationships.

\section{Gene mis-expression - a final cautionary note}

Two further messages come from these experiments. First, the unexpected viability of the fusion genes indicates the difficulty of predicting the outcome of simple mis-expressing constructs, and the need to test them before embarking on more complex strategies. Second, mis-expression experiments can give extremely mis-leading impressions of wild-type function. The female lethality of $h b-h$ arises despite $h$ 's playing no normal role in sex determination. Although $h b-h$ has proved very valuable in studying helix-loop-helix proteins and mechanisms of sex determination (Parkhurst et al. 1990), the results would have been misinterpreted without previous genetic evidence of wildtype $h$ function. Mis-regulation experiments in genetically less-well-characterised systems (e.g. vertebrates and cultured cells) should be interpreted with caution unless wild-type function is assayed independently.

We thank Diethard Tautz for sharing unpublished information and dealing patiently with our many questions; Suki Parks for suggestions and many helpful discussions. We are grateful to Paul Martin and Barbara Luke for help with and use of the scanning electron microscope. We also thank Helen Durbin, Manfred Frasch, Ulrike Gaul, Kate Hooper, Herbert Jäckle, Henry Krause, Diethard Tautz and Michael Wilcox for antibodies, and Peter Gergen, Yash Hiromi, Herbert Jäckle, Gary Struhl and Diethard Tautz for fly stocks and DNA clones used in this study. We are very grateful to Karen Downs, Peter Gergen, Yash Hiromi, Howard Lipshitz, Suki Parks and Detlef Weigel for critical reading and comments on the manuscript. We thank our colleagues in the lab (Kate Hooper, Sheena Pinchin, Mark Wainwright, Michael Lardelli, Guy Riddihough and Ilan Davis), in the ICRF Developmental Biology Unit, at Caltech and in the fly groups at Princeton for suggestions and stimulating discussions during the course of this work. S.M.P. was supported by a postdoctoral fellowship from the Helen Hay Whitney Foundation.

\section{References}

AKaM, M. (1987). The molecular basis for metameric pattern in the Drosophila embryo. Development 101, 1-22.

Carroll, S. B., Laughon, A. and Thalley, B. S. (1988) Expression, function and regulation of the hairy segmentation protein in the Drosophila embryo. Genes Dev. 2, 883-890.

Carroll, S. B. AND ScotT, M. P. (1986). Zygotically active genes that affect the spatial expression of the fushi tarazu segmentation gene during early Drosophila embryogenesis. Cell 45, 113-26

Dearolf, C. R., Topol, J. and Parker, C. S. (1989a). The caudal gene product is a direct activator of fushi tarazu transcription during Drosophila embryogenesis. Nature 341, 340-343.

Dearolf, C. R., TOPOL, J. and PARKer, C. S. (1989b)

Transcriptional control of Drosophila fusht tarazu zebra stripe expression. Genes Dev. 3, 384-398.

DiNardo, S., Kuner, J. M., Theis, J. and O'Farrell, P. H. (1985). Development of embryonic pattern in D. melanogaster as revealed by accumulation of the nuclear engrailed proten. Cell 43, 59-69.

Driever, W. AND Nusslein-Volmard, C. (1988a). The bicold protein determines position in the Drosophila embryo in a concentration-dependent manner. Cell 54, 95-104.

Driever, W. ANd NÚsSlein-Volhard, C. (1988b). A gradient of bicoid protein in Drosophila embryos. Cell 54, 83-93.

Driever, W., Thoma, G. and Nússlein-Volhard, C. (1989) Determination of spatial domains of zygotic gene expression in the Drosophila embryo by the affinity of binding sites for the bicoid morphogen. Nature 340, 363-367.

Edgar, B. A., Odell, G. M. and Schubiger, G. (1989). A genetic switch, based on negative regulation sharpens stripes in Drosophila embryos. Devl Genet. 10, 124-142.

Edgar, B. A., Weir, M. P., Schubiger, G. And Kornberg, T. (1986). Repression and turnover pattern fushi tarazu RNA in the early Drosophila embryo. Cell 47, 747-754.

ErLich, H. A. (1989). PCR Technology. New York: Stockton Press.

Frasch, M., Hoey, T., Rushlow, C., Doyle, H. and Levine, M. (1987). Characterisation and localisation of the even-skipped protein of Drosophila. EMBO J. 6, 749-759.

Frasch, M. and Levine, M. (1987). Complementary patterns of even-skipped and fushi tarazu expression involve their differential regulation by a common set of segmentation genes in Drosophila. Genes Dev. 1, 981-995.

GAUL, U. AND JÄCKLE, H. (1989). Analysis of maternal-effect 
mutant combinations elucidates regulation and function of the overlap of hunchback and Kruppel gene expression in the Drosophila blastoderm embryo. Development 107, 651-662.

Gergen, J. P. AND Butler, B. A. (1988). Isolation of the Drosophila segmentation gene runt and analysis of its expression during embryogenesis. Genes Dev. 2, 1179-1193.

Gergen, J. P. and Wieschaus, E. (1986). Dosage requirements for runt in the segmentation of Drosophila embryos. Cell 45, 289-299.

Goto, T., Macdonald, P. M. and Maniatis, T. (1989). Early and late periodic patterns of even-skipped expression are controlled by distinct regulatory elements that respond to different spatial cues. Cell 57, 413-422.

Harding, K., Hoey, T., Warrior, R. and Levine, M. (1989). Autoregulatory and gap gene response elements of the evenskipped promoter of Drosophila. EMBO J. 8, 1205-1212.

Hiromi, Y. ANd GeHring, W. J. (1987). Regulation and function of the Drosophila segmentation gene fushi tarazu. Cell 50, 963-974.

Hiromi, Y., Kuroiwa, A. and Gehring, W. J. (1985). Control elements of the Drosophila segmentation gene fushi tarazu. Cell $43,603-613$.

Hooper, K. L., Parkhurst, S. M. AND Ish-Horowicz, D. (1989) Spatial control of hairy proten expression during embryogenesis. Development 107, 489-504.

Howard, K. (1988). The generation of periodic pattern during early Drosophila embryogenesis. Development 104 Supplement $35-50$.

Howard, K. AND INGHam, P. (1986). Regulatory interactions between the segmentation genes fushi tarazu, hairy and engrailed in the Drosophila blastoderm. Cell 44, 949-957.

Howard, K., Ingham, P. and Rushlow, C. (1988). Regionspecific alleles of the Drosophila segmentation gene hairy. Genes Dev. 2, 1037-1046.

Hulskamp, M., Pfeifle, C. and Tautz, D. (1990). A morphogenetic gradient of hunchback protein organises the expression of the gap genes Kruppel and knirps in the early Drosophila embryo. Nature 346, 577-580.

Húlskamp, M., Schroder, C., Pfeifle, C., JÄckle, H. and Tautz, D. (1989). Posterior segmentation of the Drosophila embryo in the absence of a maternal posterior organizer gene. Nature 338, 629-632.

Ingham, P. W. (1988). The molecular genetics of embryonic pattern formation in Drosophila. Nature 335, 25-34.

ingham, P. W., Baker, N. E. and Martinez-Arias, A. (1988) Regulation of segment polarity genes in the Drosophila blastoderm by fushi tarazu and even-skipped. Nature 331, 73-75.

Ingham, P. W. AND Gergen, J. P. (1988). Interactions between the pair-rule genes runt, hairy, even-skipped and fushi tarazu and the establishment of periodic pattern in the Drosophile embryo. Development 104 Supplement, 51-60.

Ish-Horowicz, D. ANd Pinchin, S. M. (1987). Pattern abnormalities induced by ectopic expression of the Drosophila gene hairy are associated with repression of fushi tarazu transcription. Cell 51, 405-415.

Ish-Horowicz, D., Pinchin, S. M., Ingham, P. W. AND Gyurkovics, H. G. (1989). Autocatalytic $f t z$ activation and metameric instability induced by ectopic ftz expression. Cell 57, 223-232.

Kakidani, H. and Ptashne, M. (1988). Gal4 activates gene expression in mammalian cells. Cell 52, 161-167.

Krause, H. M., Klemenz, R. and Gehring, W. J. (1988). Expression, modification and localisation of the fushi tarazu protein in Drosophila embryos. Genes Dev. 2, 1021-1036.

Lawrence, P. A., Johnston, P., Macdonald, P. and Struhl, G. (1987). Borders of parasegments in Drosophila embryos are delimited by the fushi tarazu and even-skipped genes. Nature 328, 440-442.

Macdonald, P. M., Ingham, P. W. And Struhl, G. (1986). Isolation, structure and expression of even-skipped: a second pair-rule gene of Drosophila containing a homeobox. Cell 47, 721-734.

Macdonald, P. M. and Struhl, G. (1986). A molecular gradient in early Drosophila embryos and its role in specifying body pattern. Nature 324, 537-545.

Meinhardt, H. (1982). Models of Btological Pattern Formation. London: Academic Press.

Nusslein-Volhard, C., Frohnhofer, H. G. and Lehmann, R. (1987). Determination of anteroposterior polarity in Drosophila. Science 238, 1675-1681.

Nússlein-Volhard, C. and Wieschaus, E. (1980). Mutations affecting segment number and polarity in Drosophila. Nature 287, 795-801.

Pankratz, M. J., Нoch, M., Seifert, E. and Jäckle, H. (1989). Krüppel requirement for knirps enhancement reflects overlapping gap gene activities in the Drosophila embryo. Nature 341, 337-340.

Pankratz, M. J., Seifert, E., Gerwin, N., Billi, B., Nauber, U. AND JÄCKLE, H. (1990). Gradients of Kruppel and knirps gene products direct pair-rule gene stripe patterning in the posterior region of the Drosophila embryo. Cell 61, 309-317.

Parkhurst, S. M., Bopp, D. and Ish-Horowicz, D: (1990). X:A ratio, the primary sex determining signal in Drosophila, is transduced by helix-loop-helix proteins. Cell 63, 1179-1191.

Patel, N. H., Martin-Bianco, E., Coleman, K. G., Poole, S. J., Elus, M. C., KornberG, T. B. and Goodman, C. S. (1989) Expression of engrailed protein in arthropods, annelids and chordates. Cell 58, 955-968.

Rushlow, C. A., Hogan, A., Pinchin, S. M., Howe, K. M., Lardelli, M. T. AND Ish-Horowicz, D. (1989). The Drosophila hairy protein acts in both segmentation and bristle patterning and shows homology to N-myc. EMBO J. 8, 3095-3103.

Schrodder, C., Tautz, D., Seifert, E. and Jackle, H. (1988). Differential regulation of the two transcripts from the Drosophila gap segmentation gene hunchback. EMBO J.7, 2881-2887.

Schupbach, T., Wieschaus, E. and Nơthiger, R. (1978). The embryonic organisation of the genital disc studied in genetic mosaics of Drosophila melanogaster. Wilhelm Roux's Arch. Devl Biol. 185, 249-270.

SpRAdung, A. C. (1986). P element-mediated transformation. In Drosophila, a Practical Approach (ed. D. B. Roberts) pp. 175-197, Oxford: IRL Press.

Stanojevic, D., Hoey, T. and Levine, M. (1989). Sequence specific DNA-binding activities of the gap proteins encoded by hunchback and Krippel in Drosophila. Nature 341, 331-335.

Steller, H. ANd PirrotTa, V. (1985). A transposable P vector that confers $\mathrm{G} 418$ resistance to Drosophila larvae. EMBO J. 4 , 167-171.

Steward, R., Zusman, S. B., Huang, L. H. and Schedl, P. (1988). The dorsal protein is distributed in a gradient in early Drosophila embryos. Cell 55, 487-495.

STRUHL, G. (1985). Near-reciprocal phenotypes caused by inactivation or indiscriminate expression of the Drosophila segmentation gene $\mathrm{ftz}$. Nature 318, 677-680.

STRUHL, G. (1988). Morphogen gradients and the control of body pattern in insect embryos. In Cellular Basis of Morphogenesis (ed. D. Evered and J. Marsh) Ciba Foundation Symposium 144, pp. 65-91, Chichester, UK: J. Wiley and Sons.

STRUHL, G. (1989). Differing strategies for organising anterior and posterior body patterns in Drosophila embryos. Nature 338, 741-744.

Struhl, G., Struhl, K. and Macdonald, P. M. (1989). The gradient morphogen bicoid is a concentration-dependent transcriptional activator. Cell 57, 1259-1273.

TAUTZ, D. (1988). Regulation of the Drosophila segmentation gene hunchback by two maternal morphogenetic centres. Nature 332, 281-284.

Tautz, D., Lehmann, R., Schnurch, H., Schum, R., Seifert, E., KIENLIN, A., JoNes, K. AND JäCKLE, H. (1987). Finger protein of novel structure encoded by hunchback, a second member of the gap class of Drosophila segmentation genes. Nature 327, 383-389.

Tautz, D. and Pfeifle, C. (1989). A non-radioactive in situ hybridization method for the localization of specific RNAs in Drosophila embryos reveals translational control of the segmentation gene hunchback. Chromosoma 98, 81-85. 
Ueda, H., Sonoda, S., Brown, J. L., Scott, M. P. and Wu, C. (1990). A sequence-specific DNA-binding protein that activates fushi tarazu segmentation gene expression. Genes Dev. 4 , 624-635.

Webster, N., Jin, J. R., Green, S., Hollus, M. and Chambon, P. (1988). The yeast UAS $_{\mathrm{G}}$ is a transcriptional enhancer in human HeLa cells in the presence of the GAL4 trans-activator. Cell $\mathbf{5 2}$ 169-178.

Weir, M. P. ANd Korngerg, T. (1985). Pattern of engrailed and fushi tarazu transcripts reveal novel intermediate stages in Drosophila segmentation. Nature 318, 433-39.

Wieschaus, E. ANd Nússlein-Volhard, C. (1986). Looking at embryos. In Drosophla, a Practical Approach (ed. D. B. Roberts) pp. 175-197, Oxford: IRL Press.

(Accepted 7 January 1991) 